\title{
EDITOR'S REPORT \\ 2007-2008
}

1) The 104-page issue of the Proceedings of the Nova Scotian Institute of Science Volume 44 Part 1 published in the summer of 2007 included papers providing a profile of the life and times of Donald Olding Hebb Canada's greatest psychologist, a review of deepwater corals research in Atlantic Canada, and an account of the biological and environmental requisites for a successful shrimp trap fishery written as a tribute to Michael Newell the fisherman who developed the fishery. In addition, the issue contained several shorter articles (The Woodville Ice Cave, Records of the occurrence of a non-native fish and the student prizewinning paper on Rhodotorula glutinis by $\mathrm{M}$. Jason MacDonald and Godwin D'Cunha.

2) As the photo-reproduction copies of the Flora of Nova Scotia produced in 2005 were almost sold out, a new photo-reproduction was undertaken. The original printing [Part 1 (1963 - 1964), Part II (1969)] was scanned and combined into a single large issue as before and the 100 copies were offered for sale in the summer of 2007. Again this is an exact copy of the original NSIS publication of the Flora of Nova Scotia; we have been particularly pleased with the quality of this scanning and the finished copy. Fortunately, the costs of the reproduction were low enough for this photo-reproduction to be sold for the same price (\$35) as the previous 2005 volume.

3) Preparation of the PNSIS Volume 44 Part 2 is in hand. Currently a number of papers are being processed and publication is expected to be completed in the summer of 2008 in time for its circulation prior to the coming lecture season.

Respectfully submitted to the AGM

May 5, 2008

James E. Stewart

Editor PNSIS 